\title{
A $~ 4000$ year record of hydrologic variability from the Olympic Mountains, Washington
}

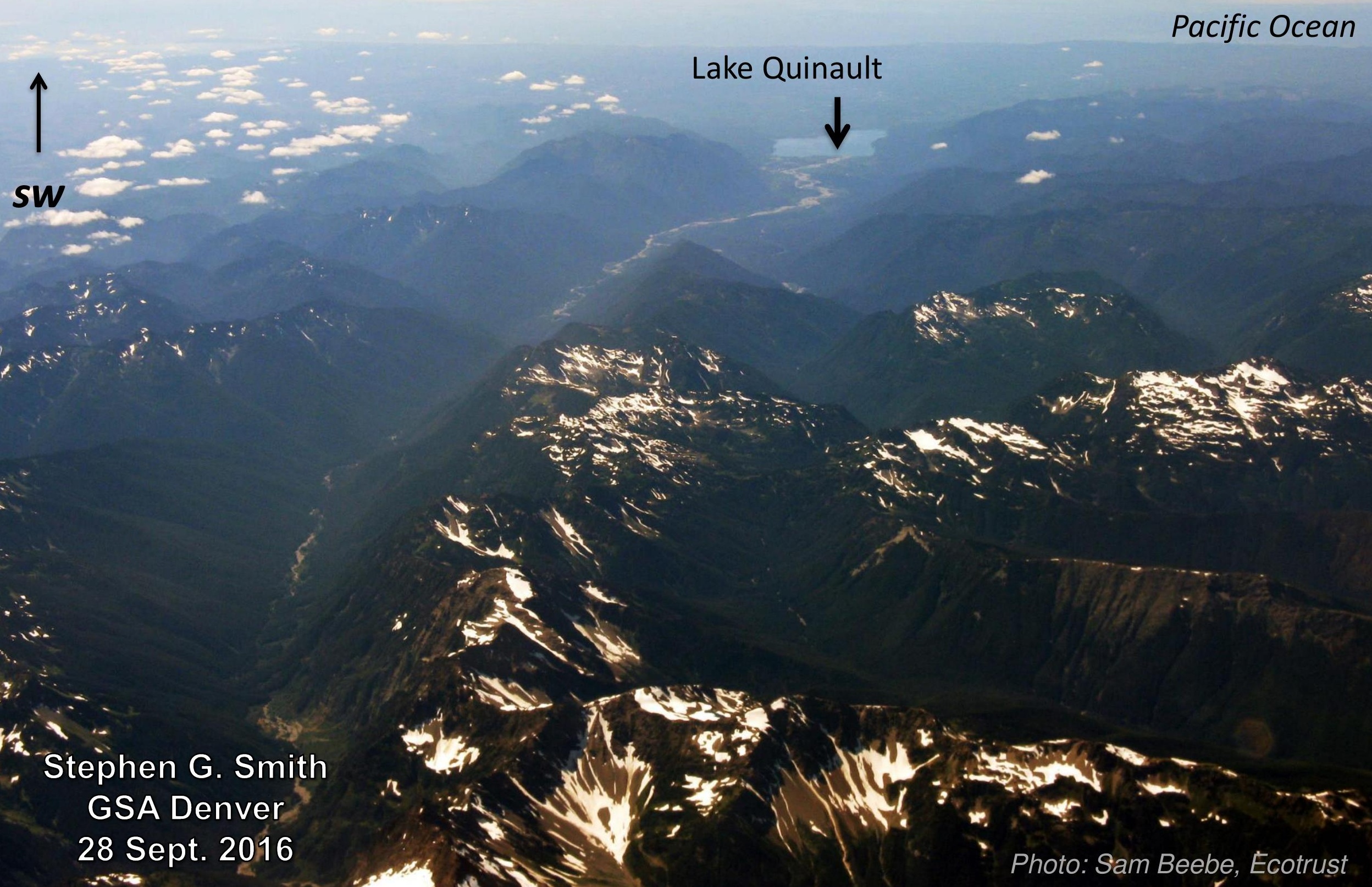




\section{Research Questions}

- Flood history from Lake Quinault...?

- $\mu X R F$ as a proxy...?

- Future of extreme events...? 


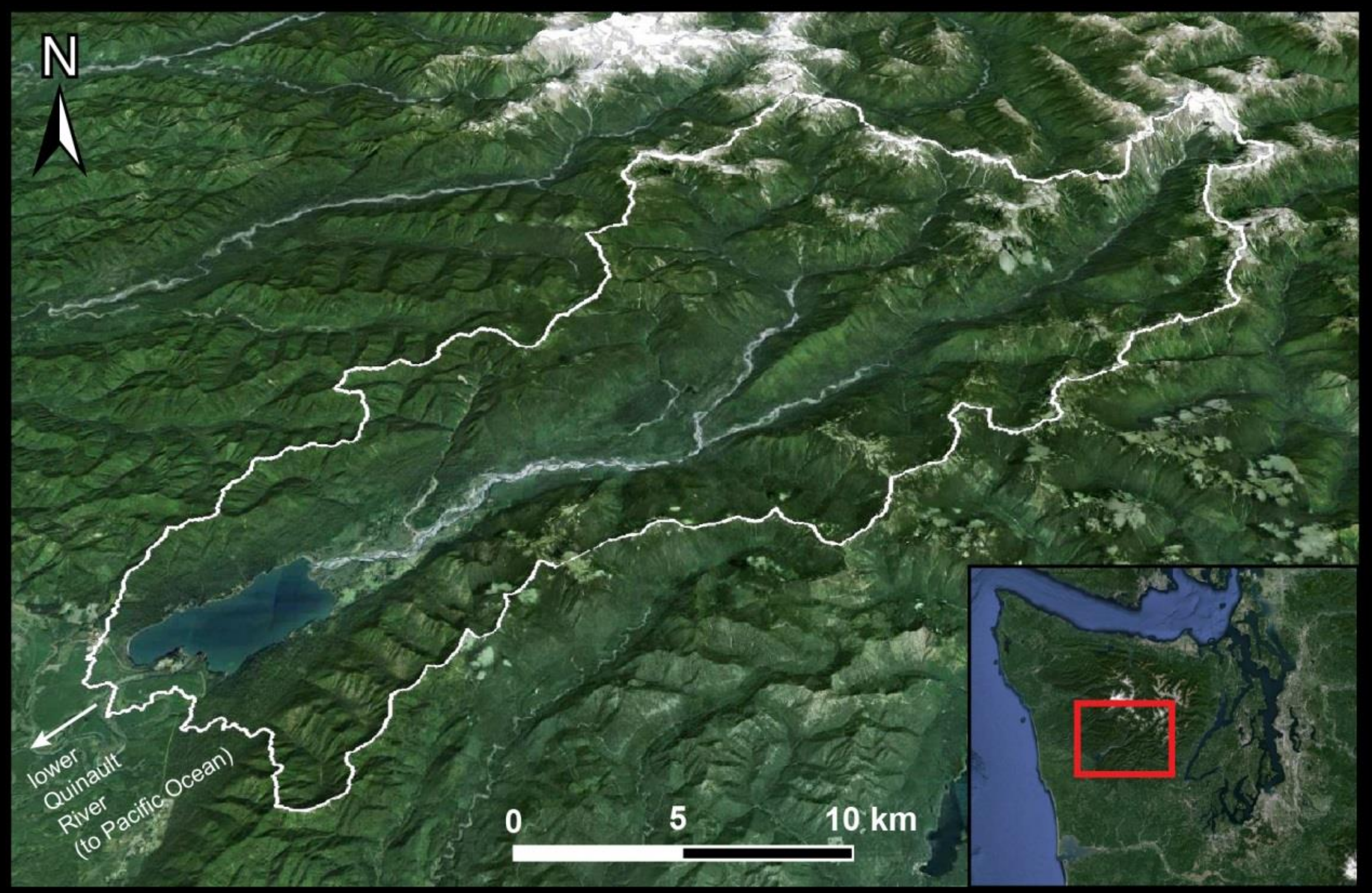




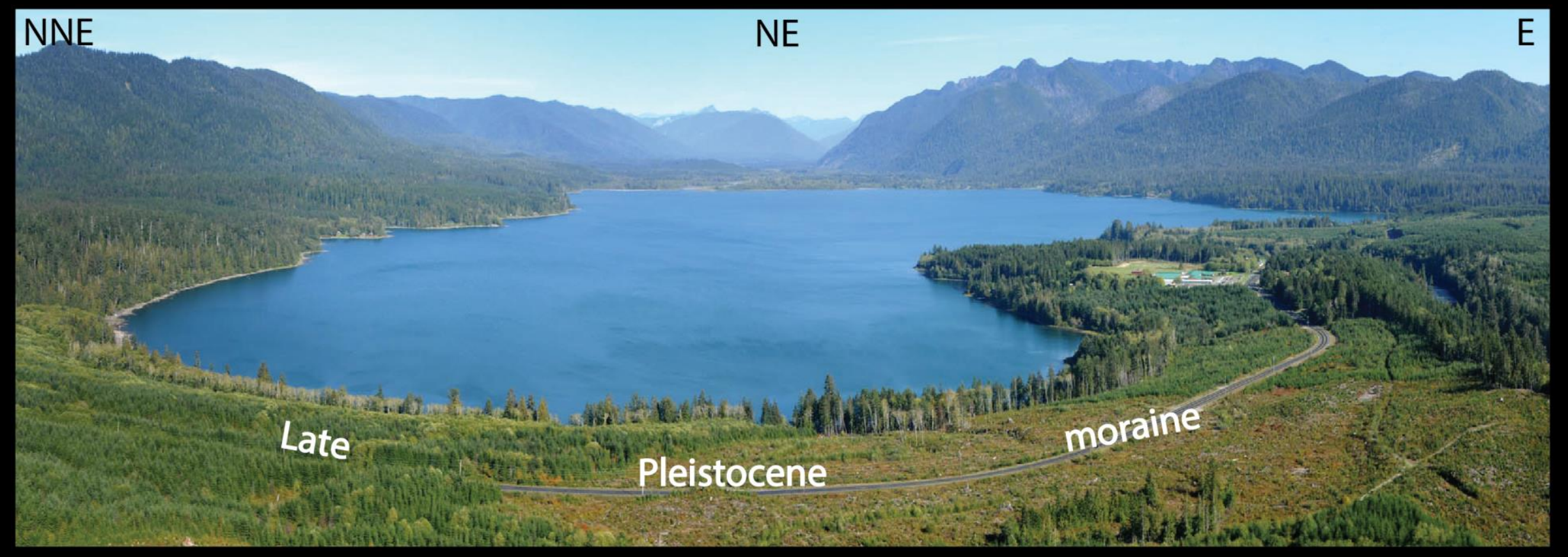

Photo: Larry Workman, Quinault Indian Nation 


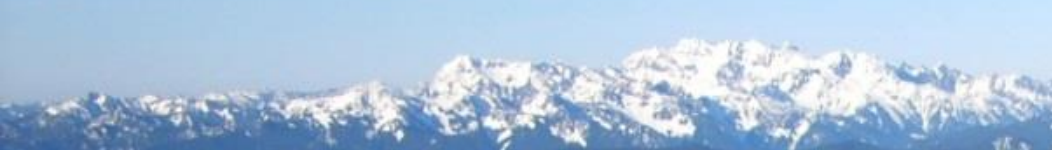

$-x^{2}+\cdots+\cdots$
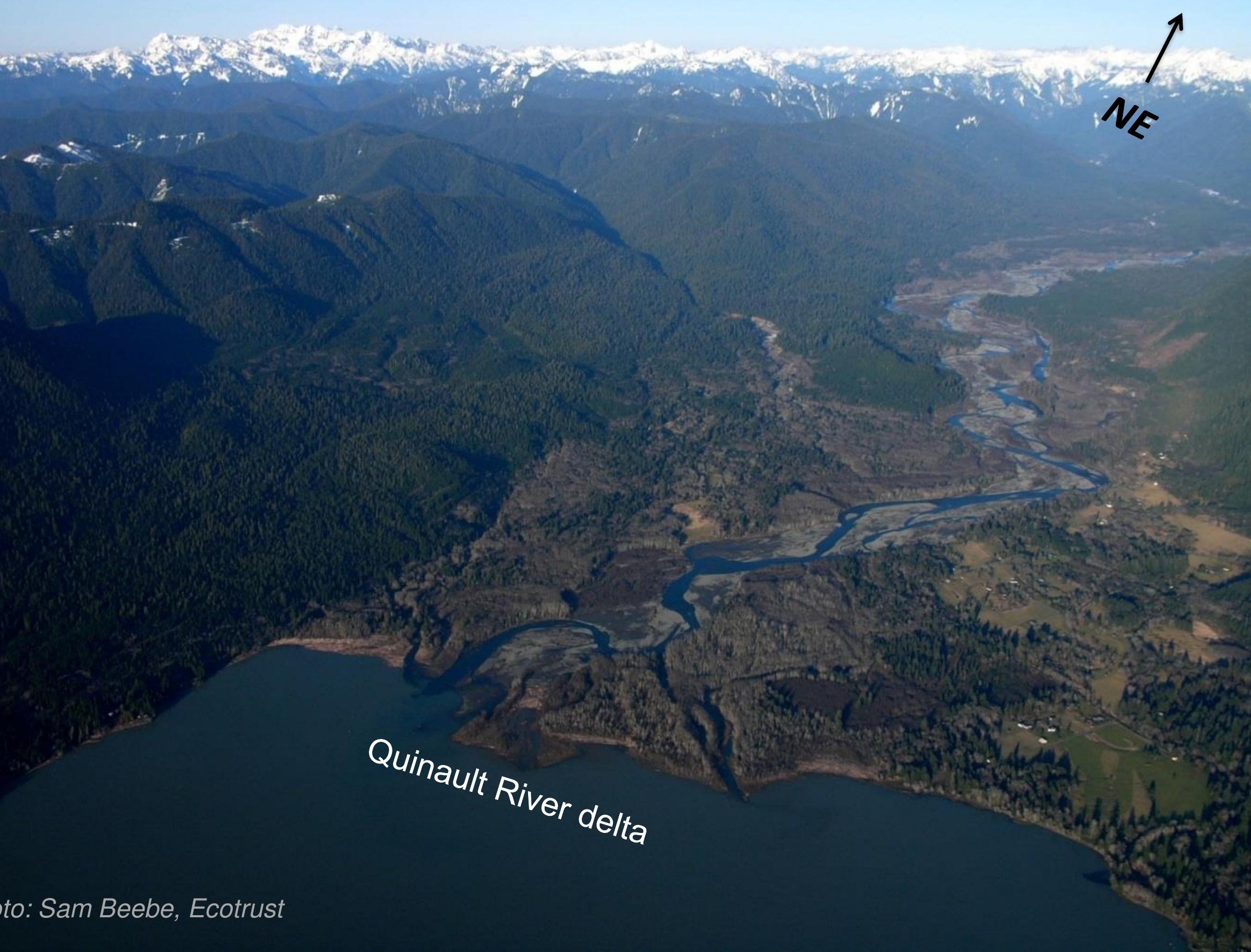
High lake turbidity following a large storm

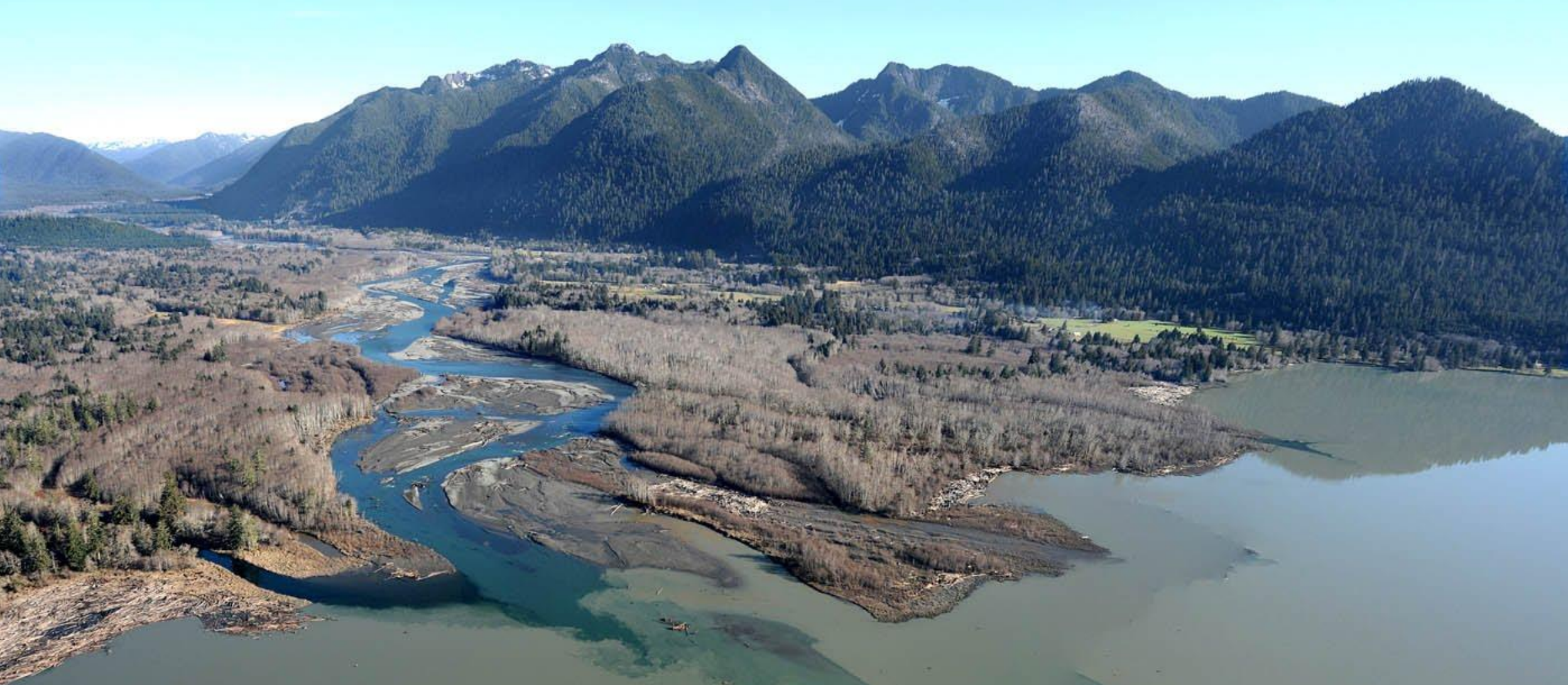




\section{Methods}
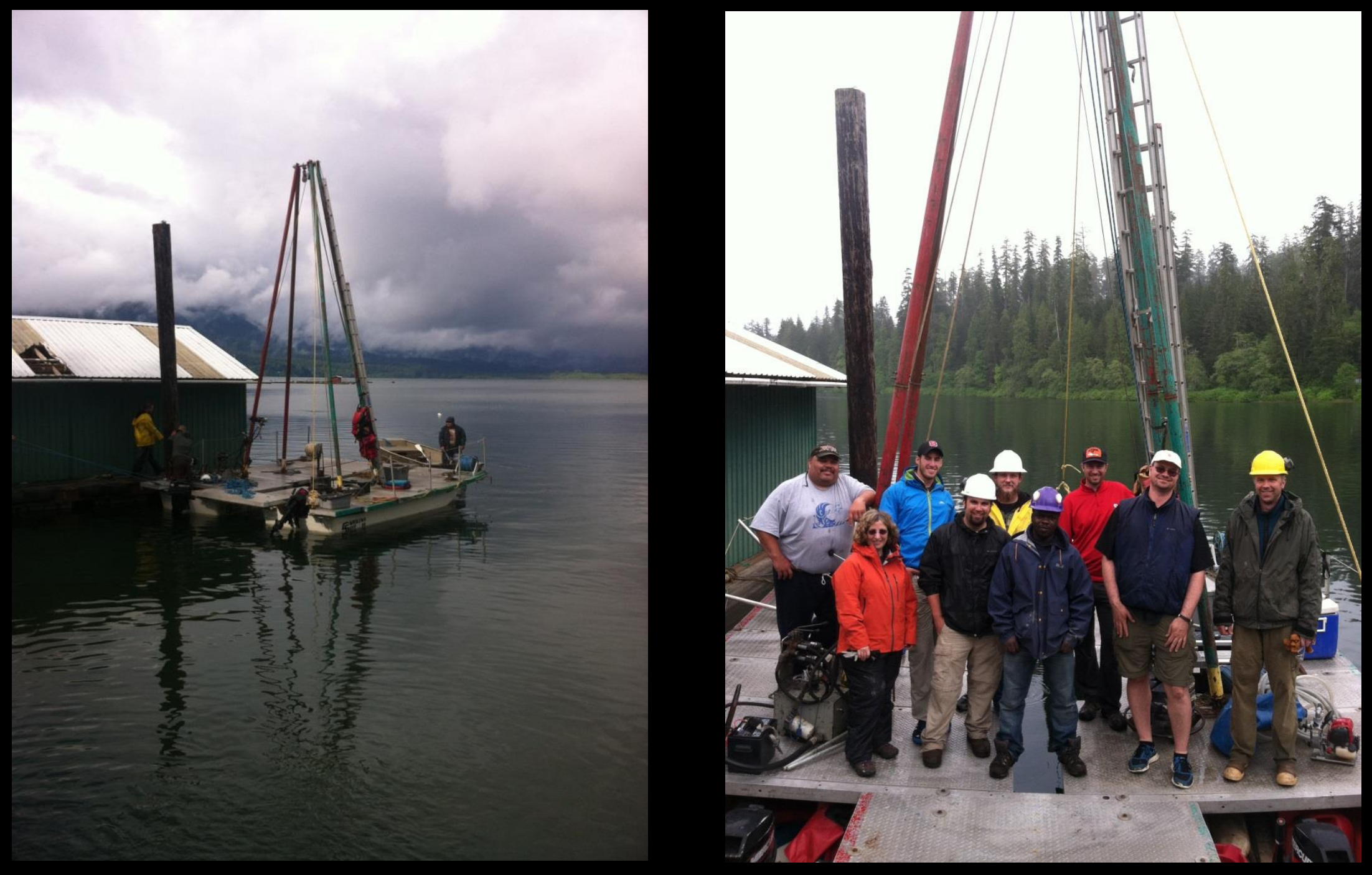


\section{Core locations}

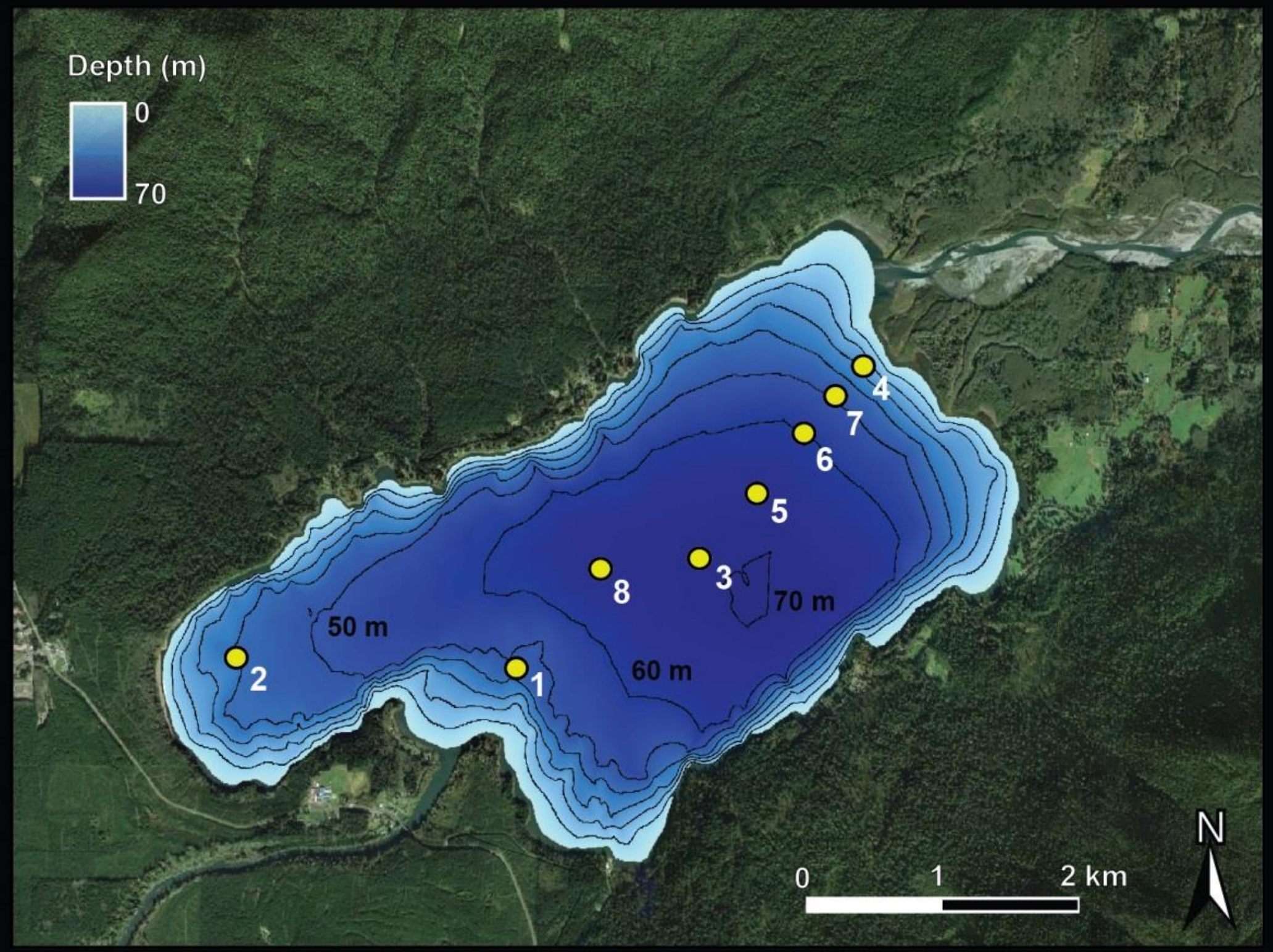




\section{Gravity cores}

DISTAL

$\leftarrow$

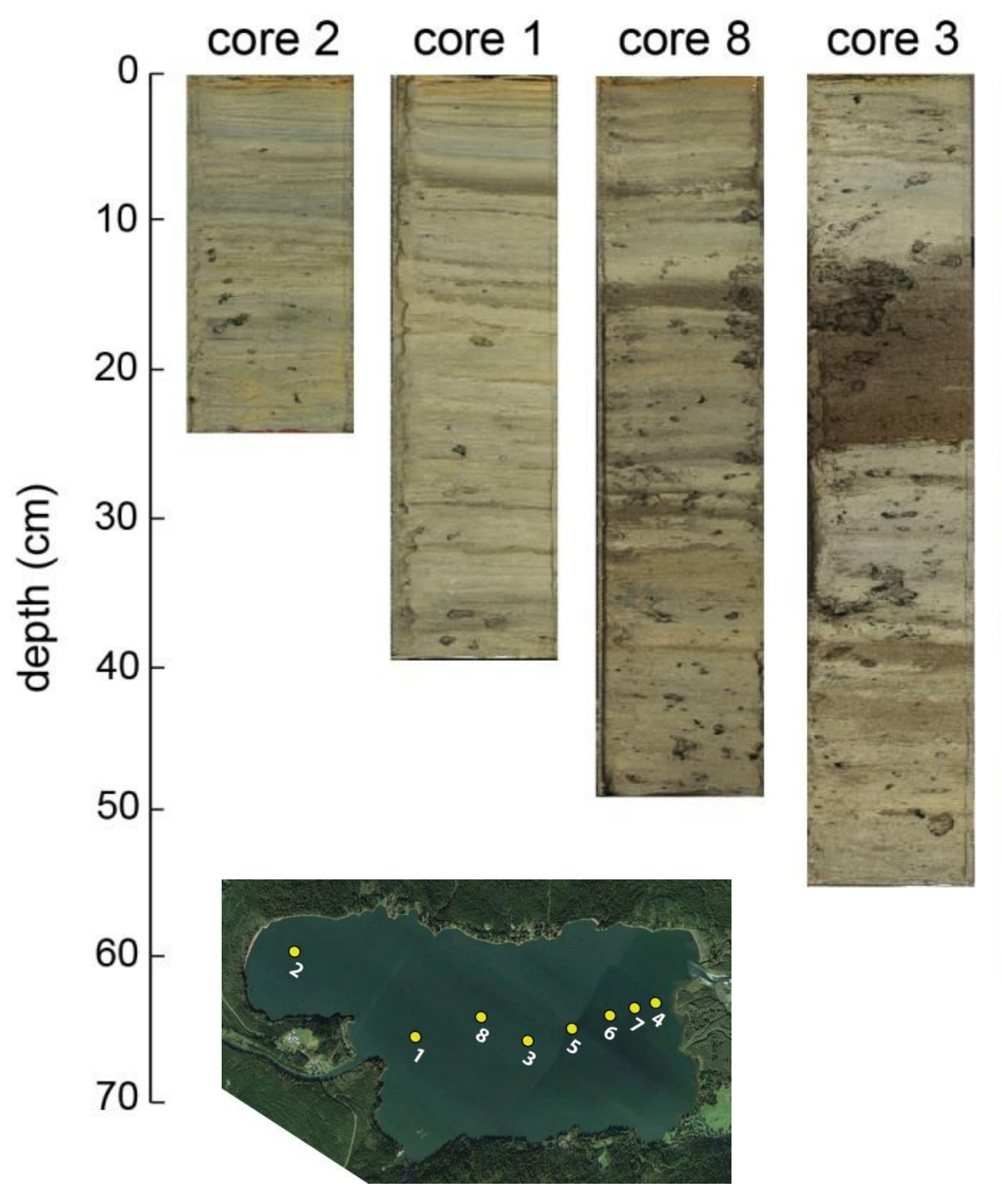

PROXIMAL
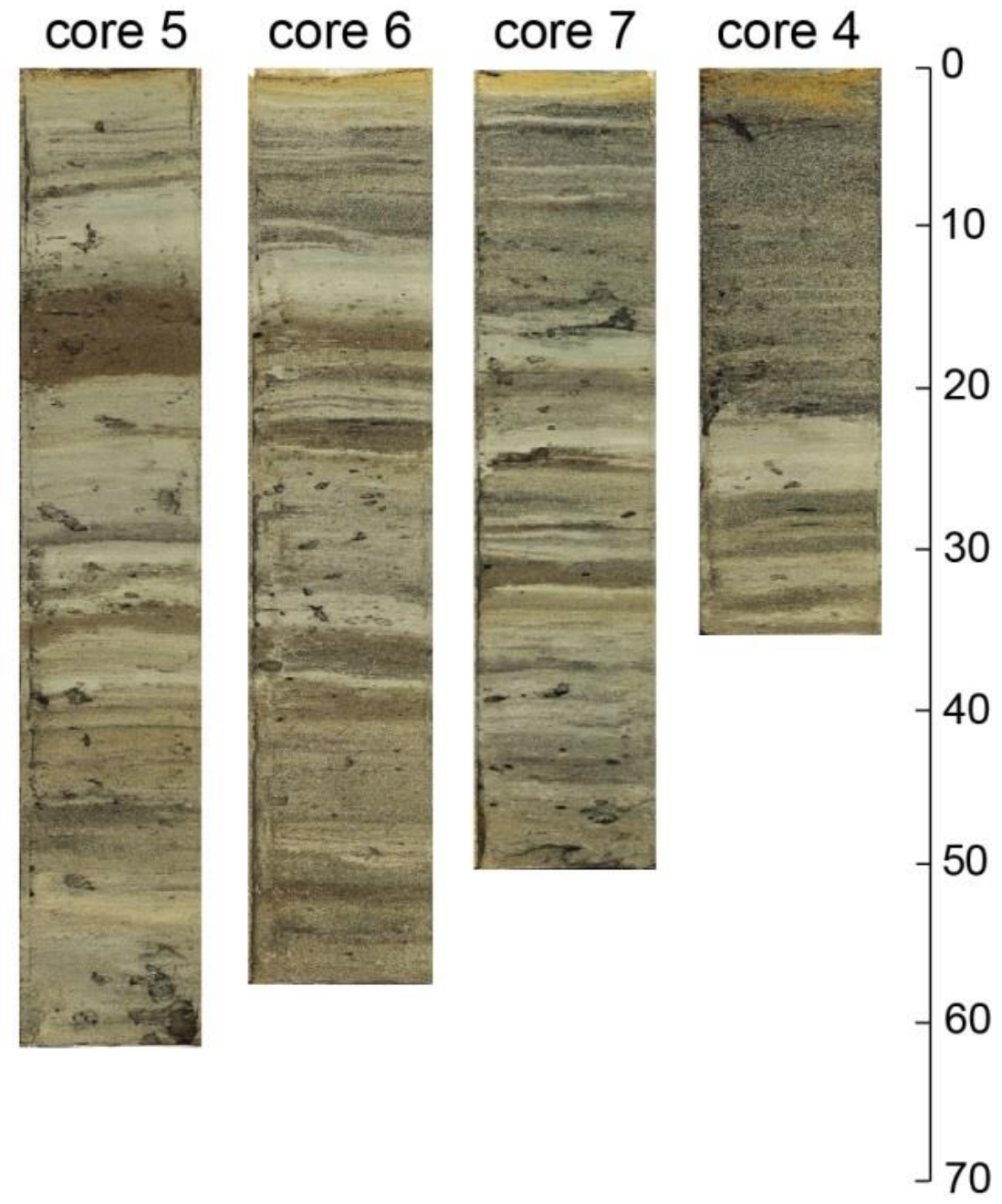


\section{Gravity cores}

DISTAL

PROXIMAL

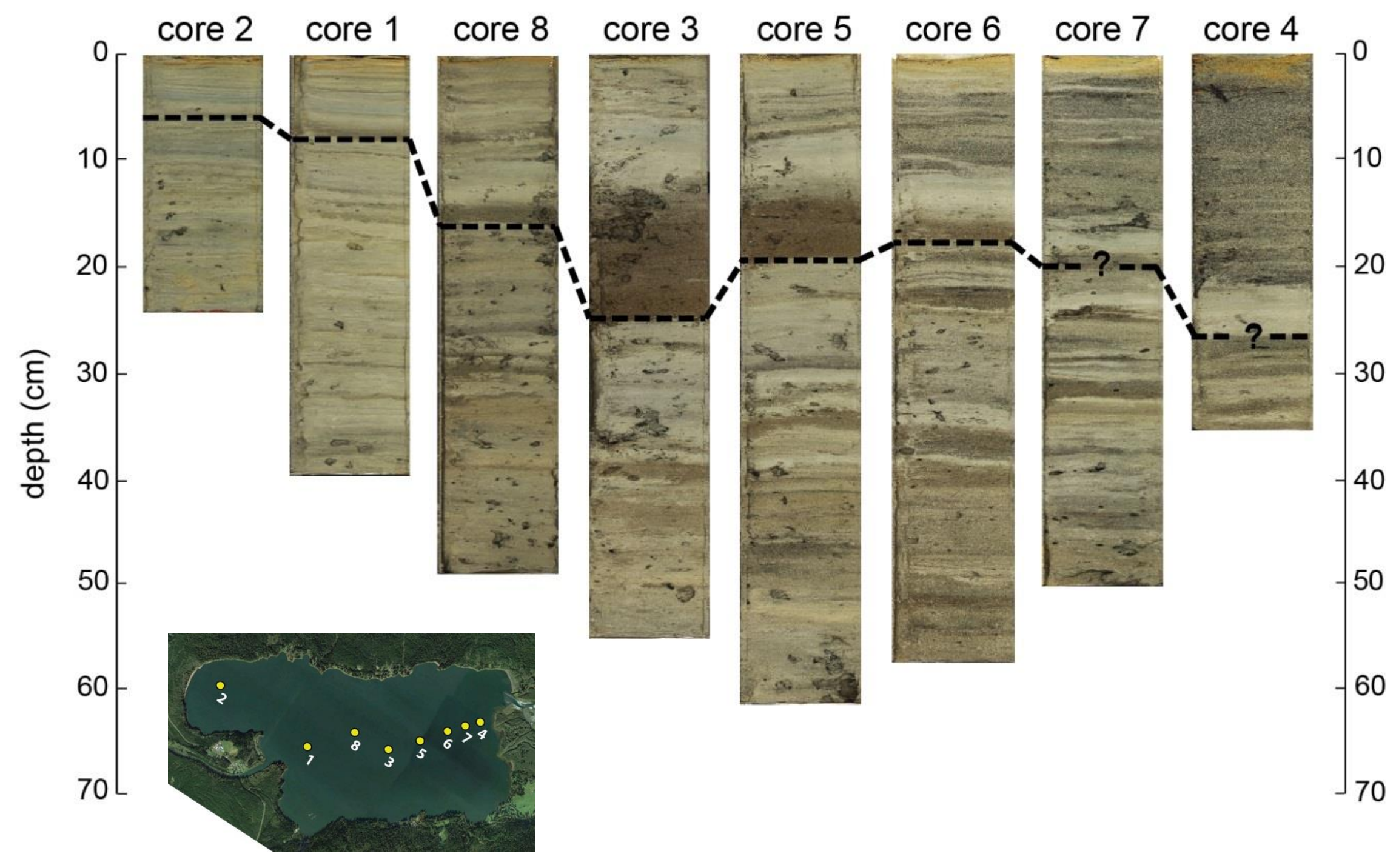


Core 1
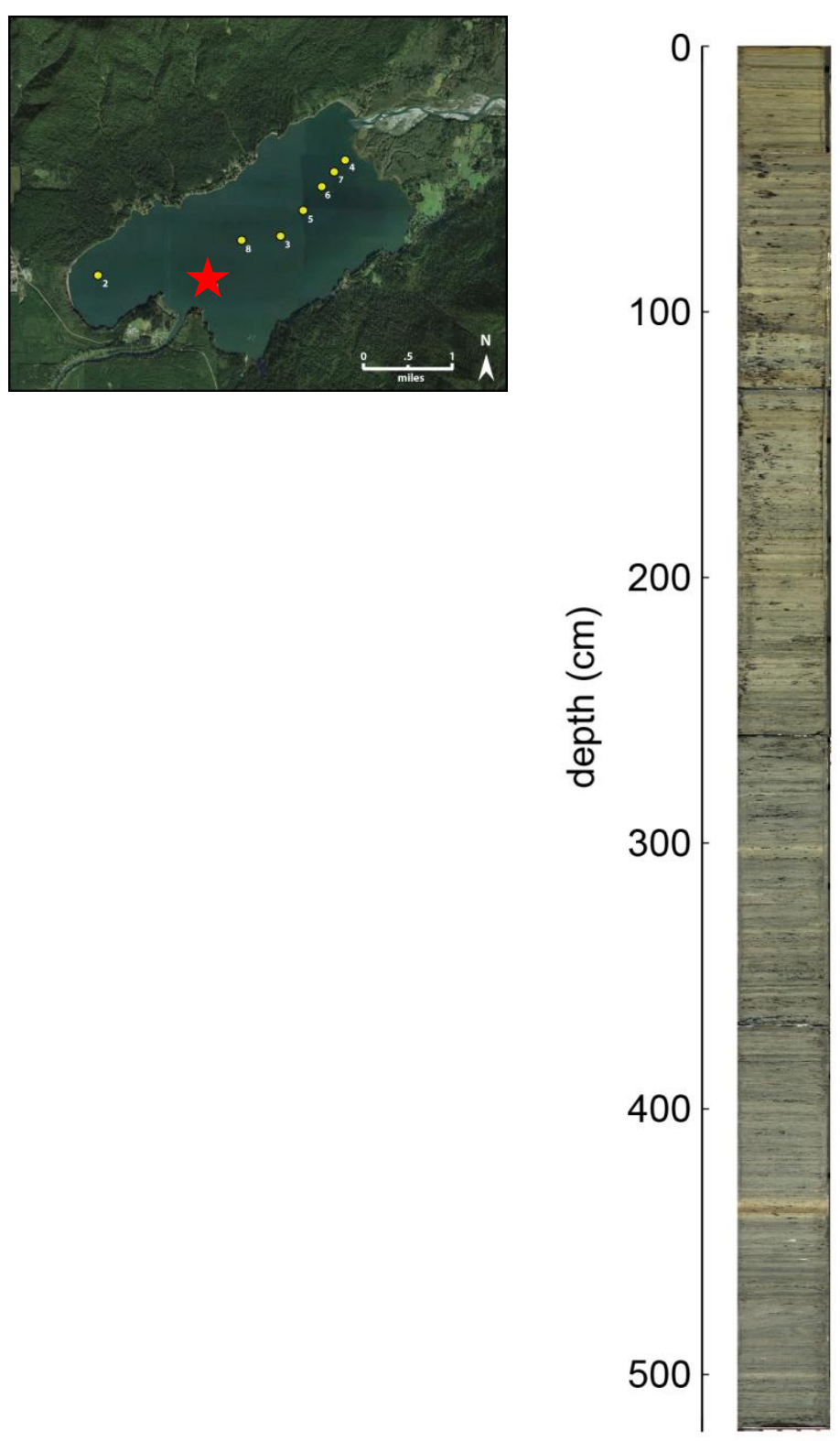

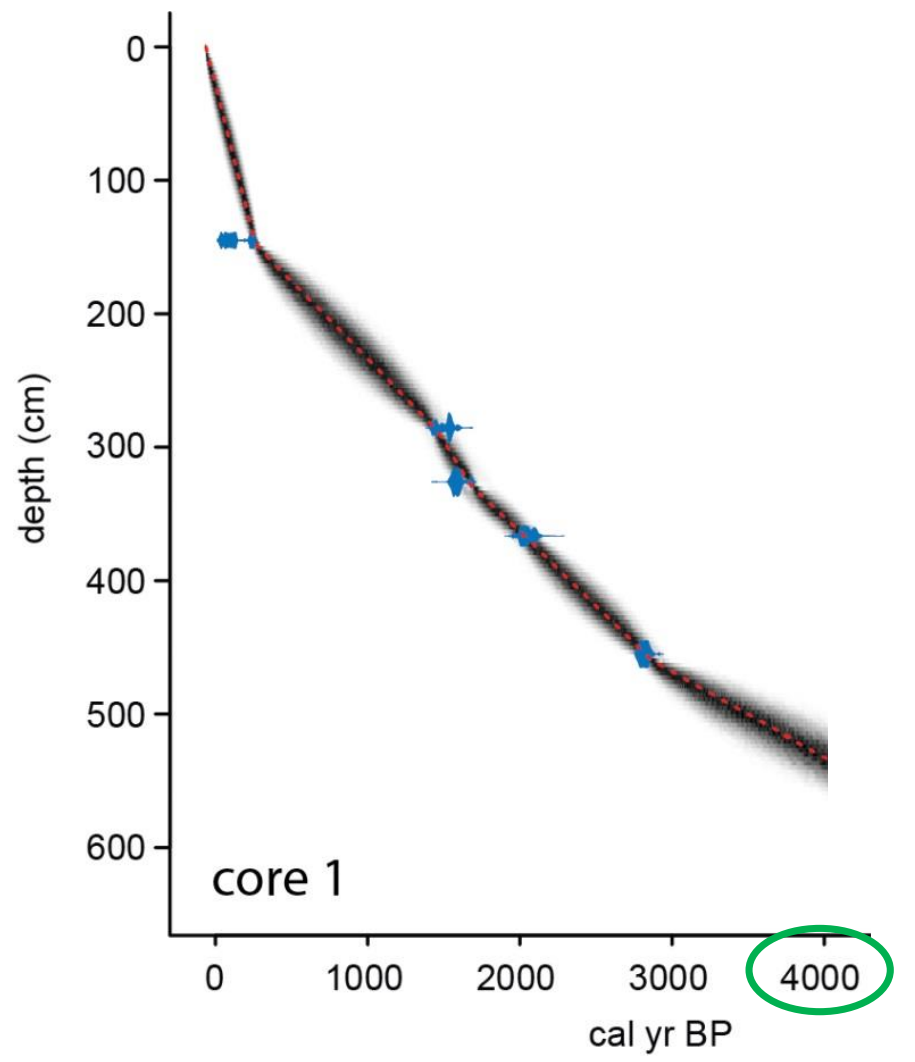




\section{Core-scanning $\mu \mathrm{XRF}$}

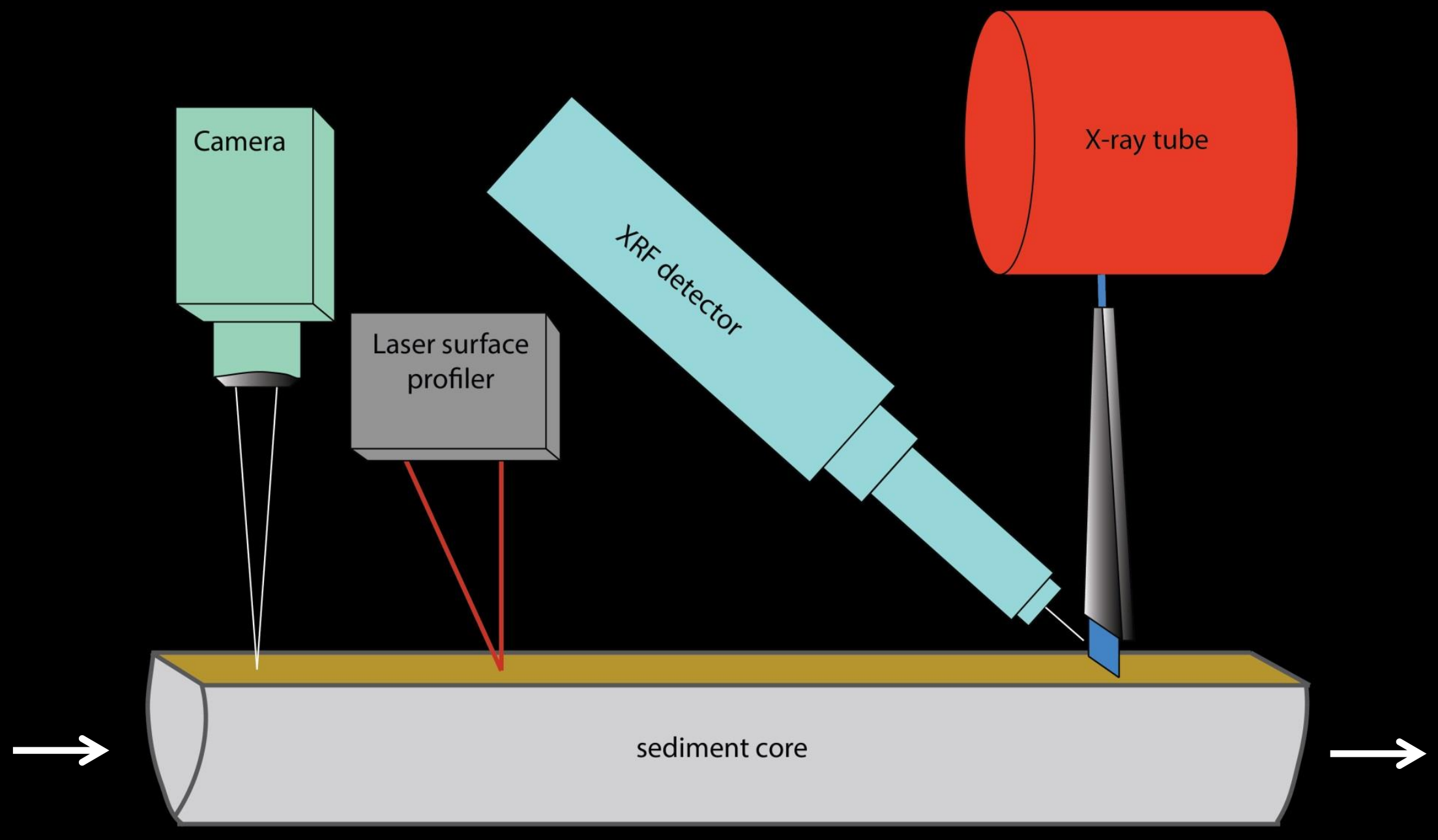




\section{Core 1}
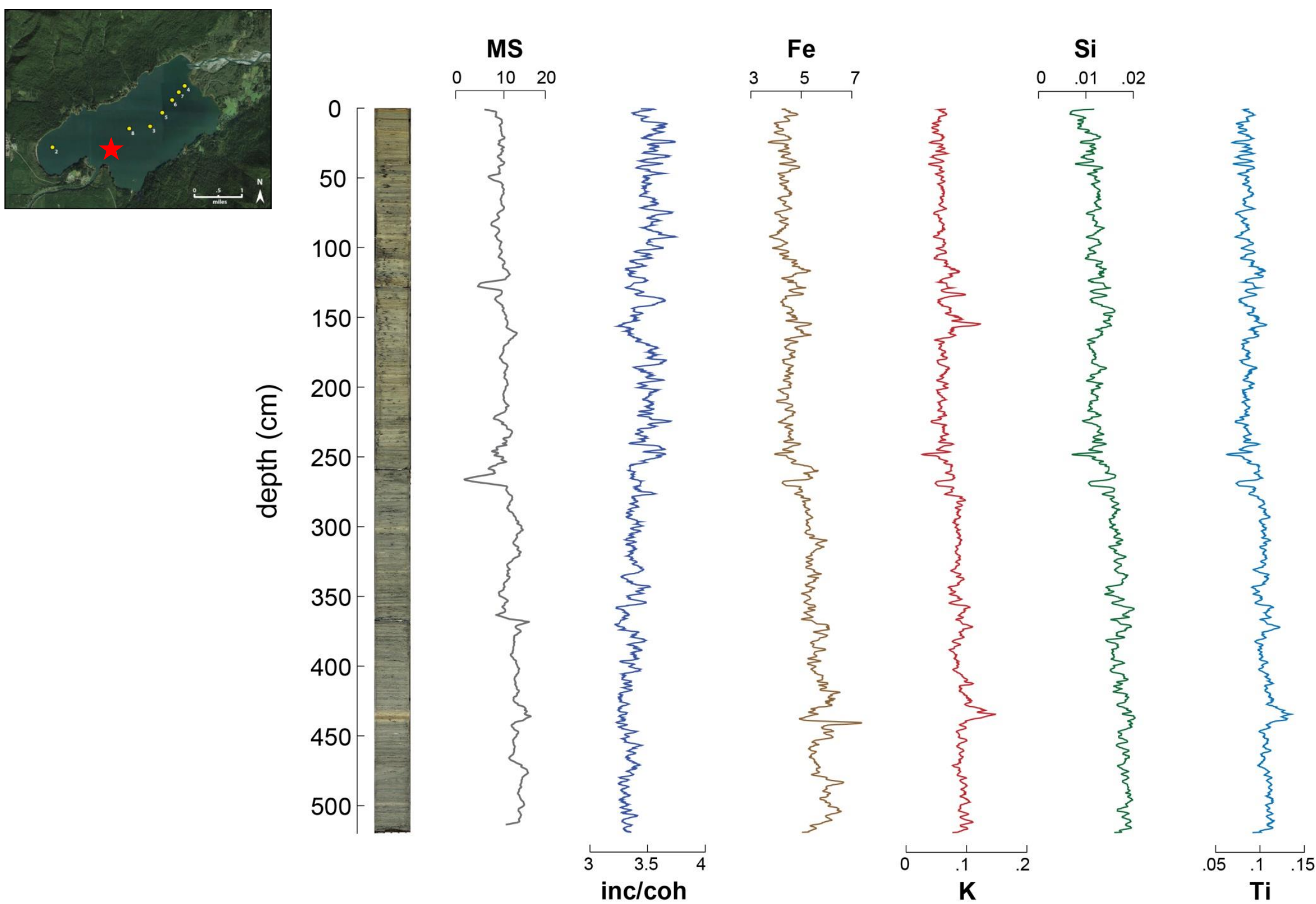


\section{Core 3}
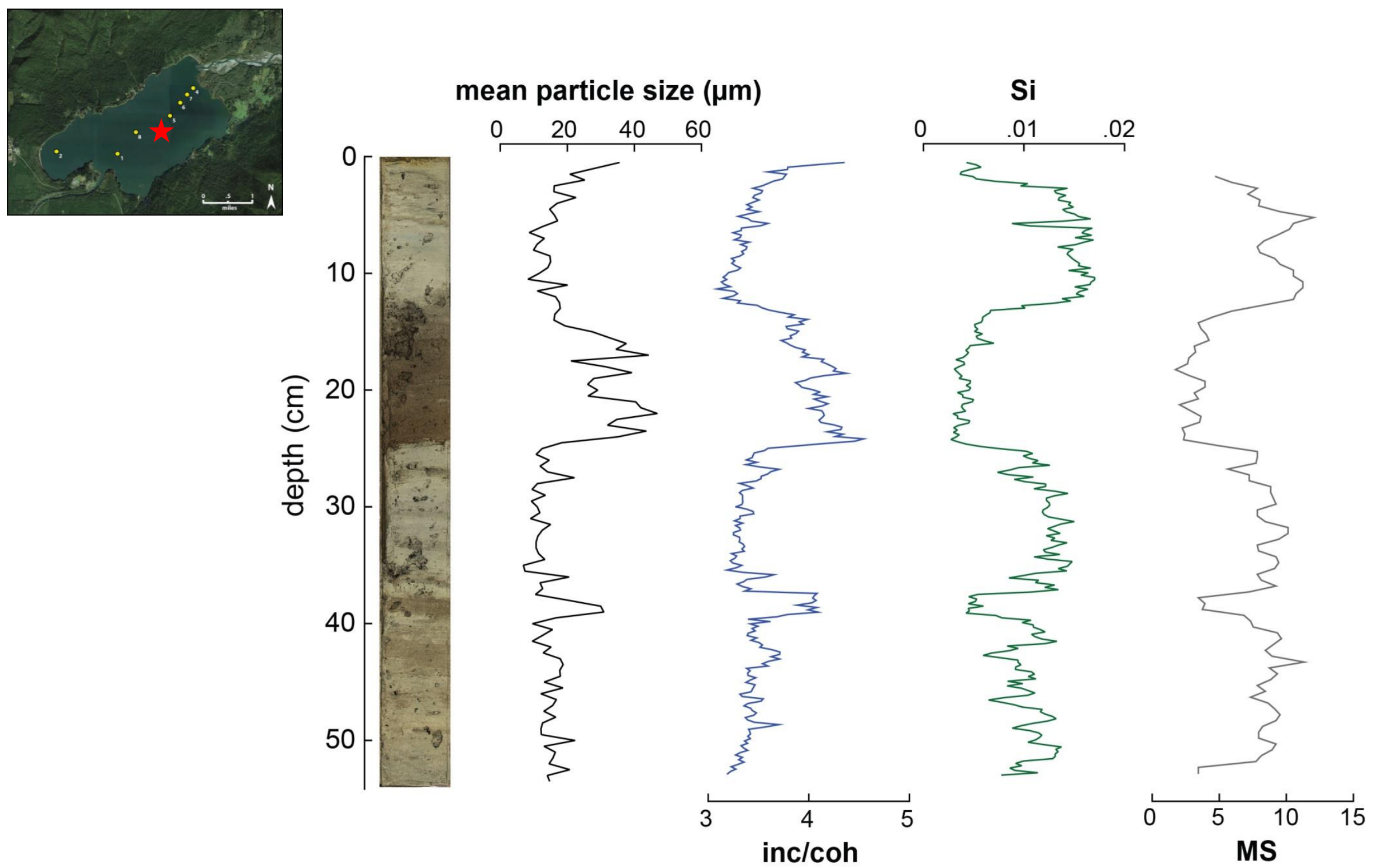


\section{Core 3}
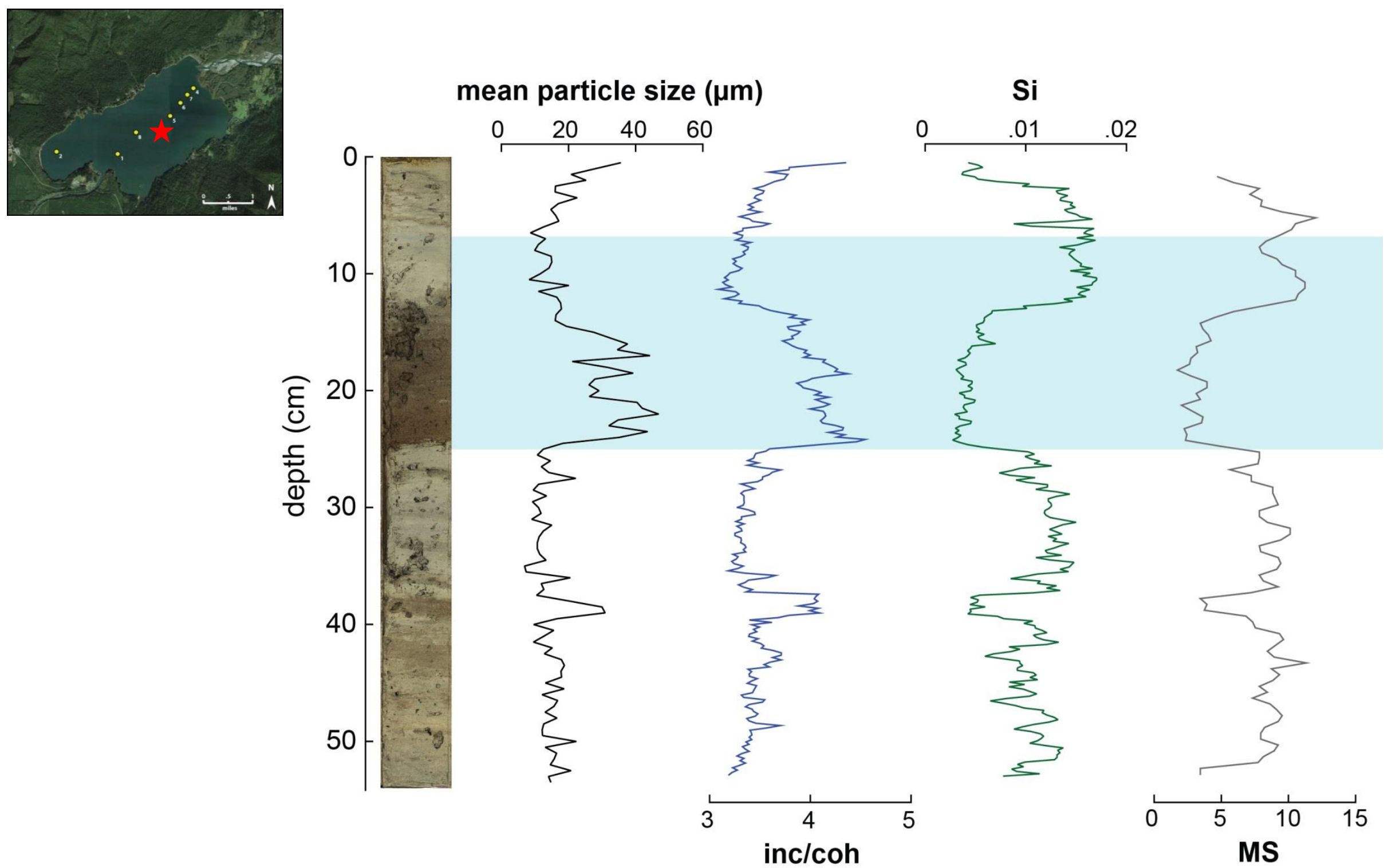


\section{Core 3}
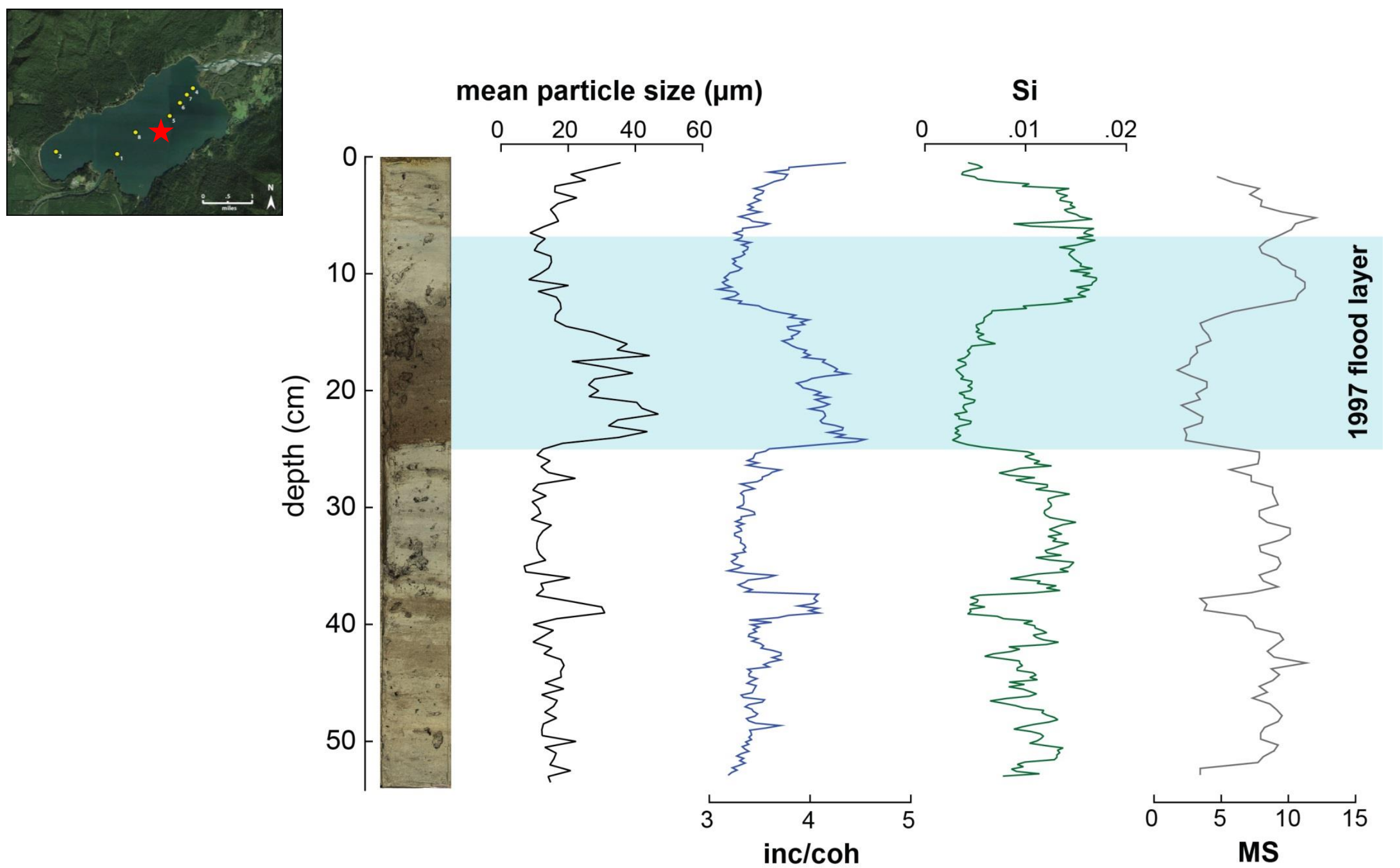
Core 1

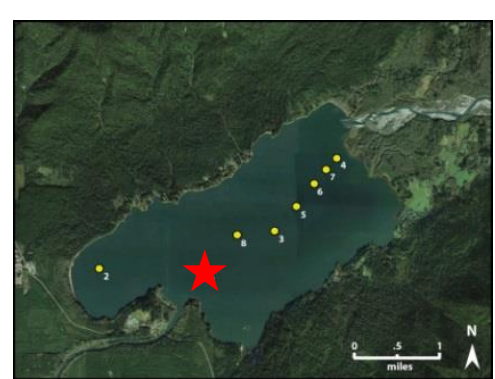

\section{Identifying extreme flood} events...

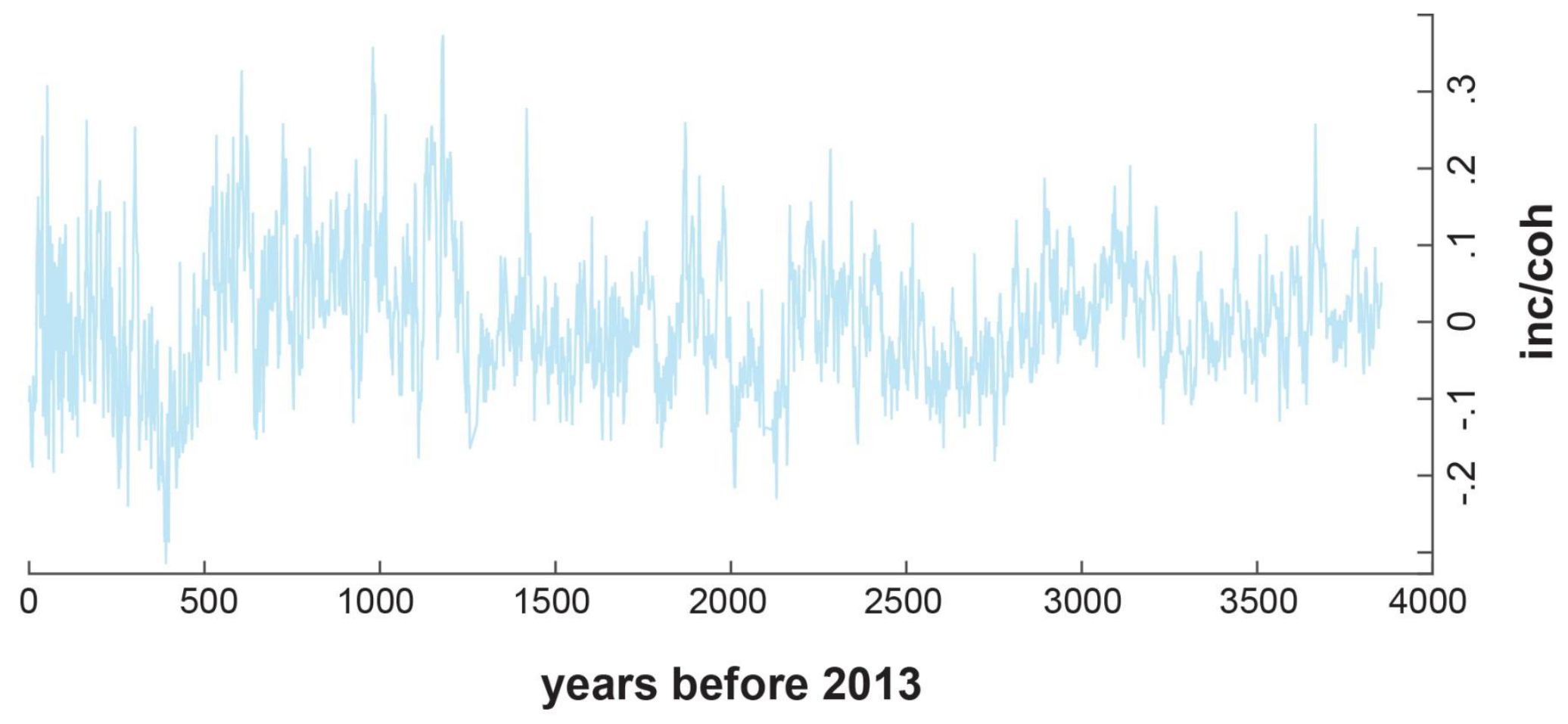




\section{Core 1}
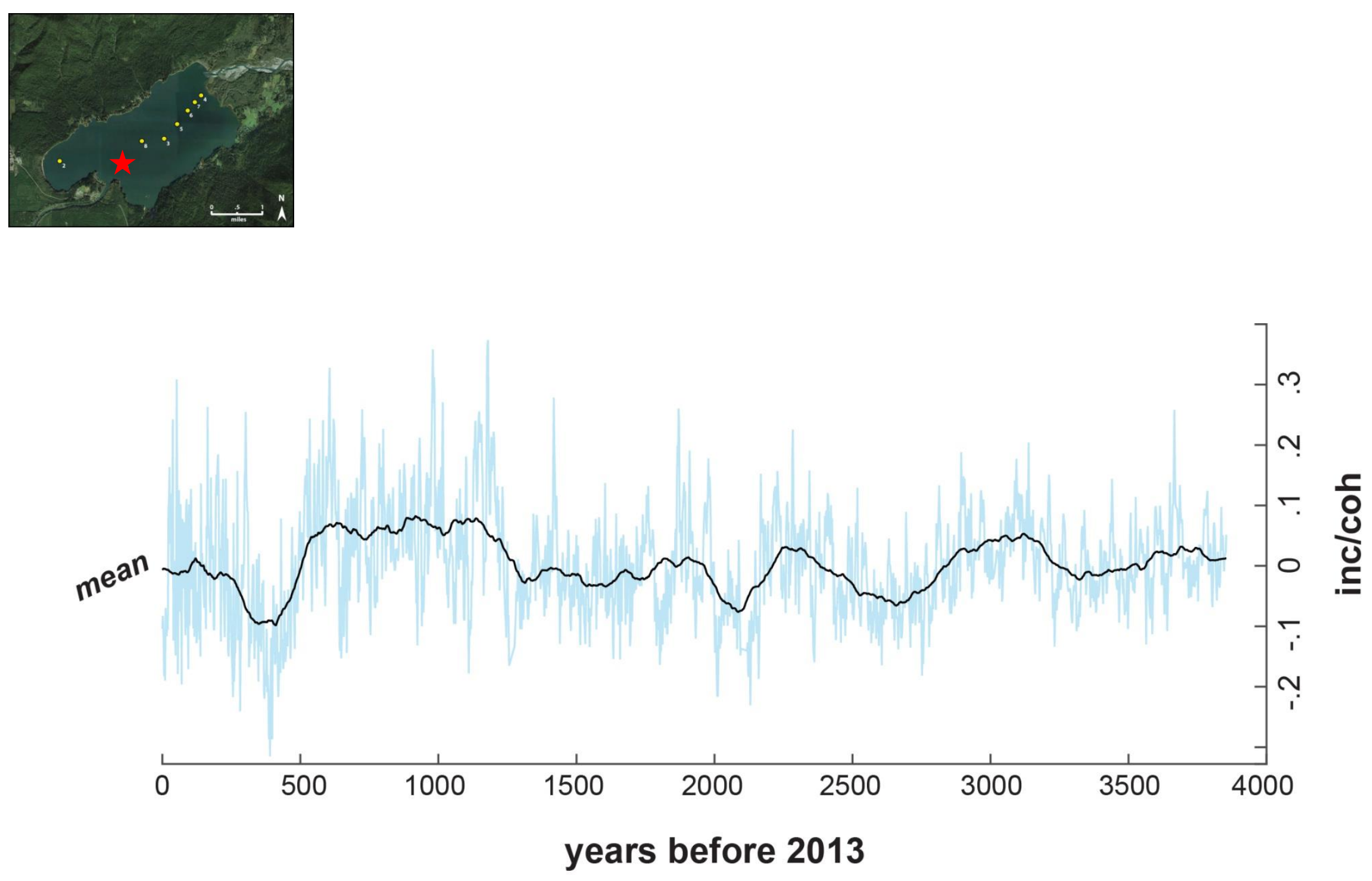


\section{Core 1}
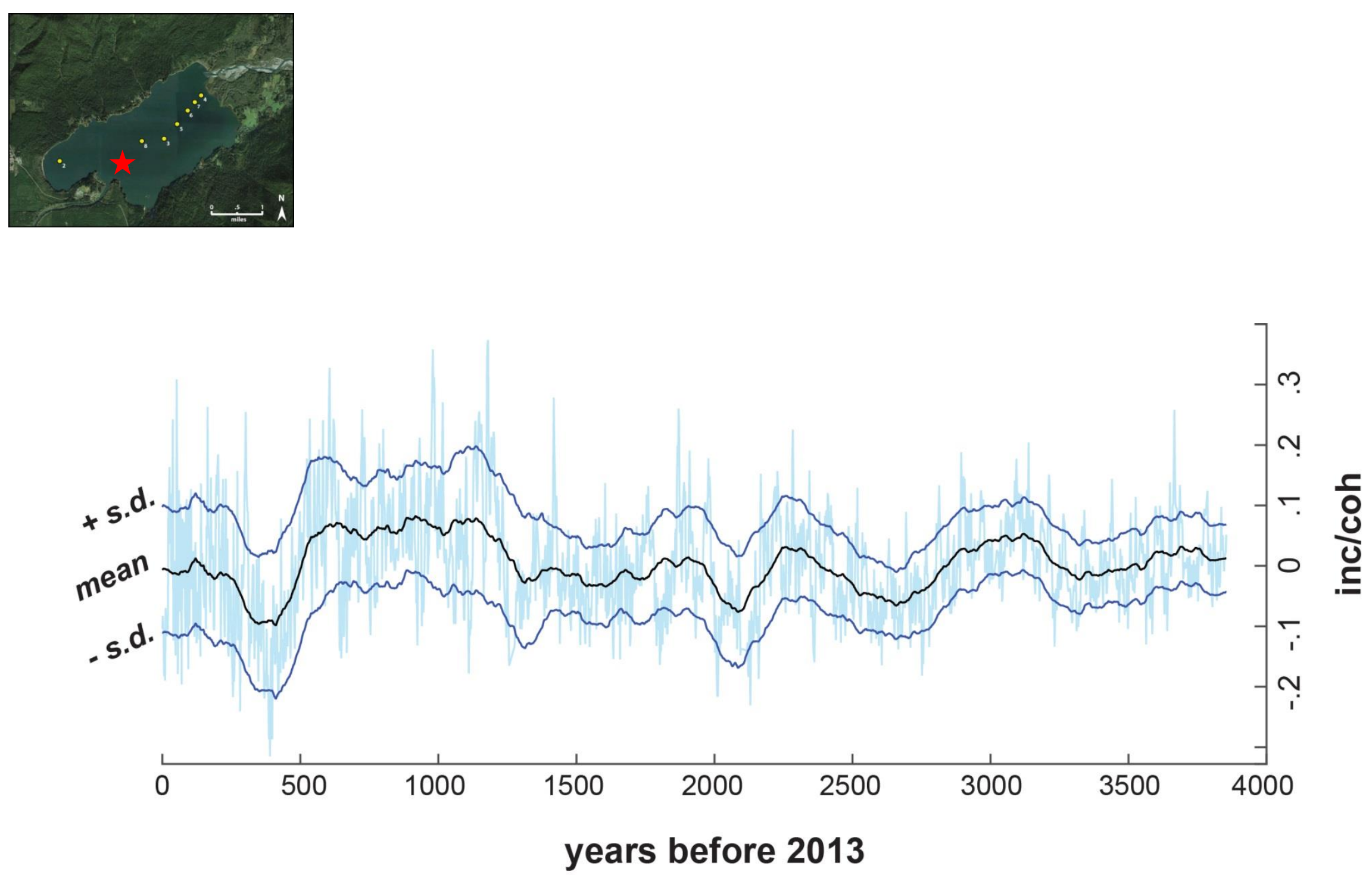


\section{Core 1}
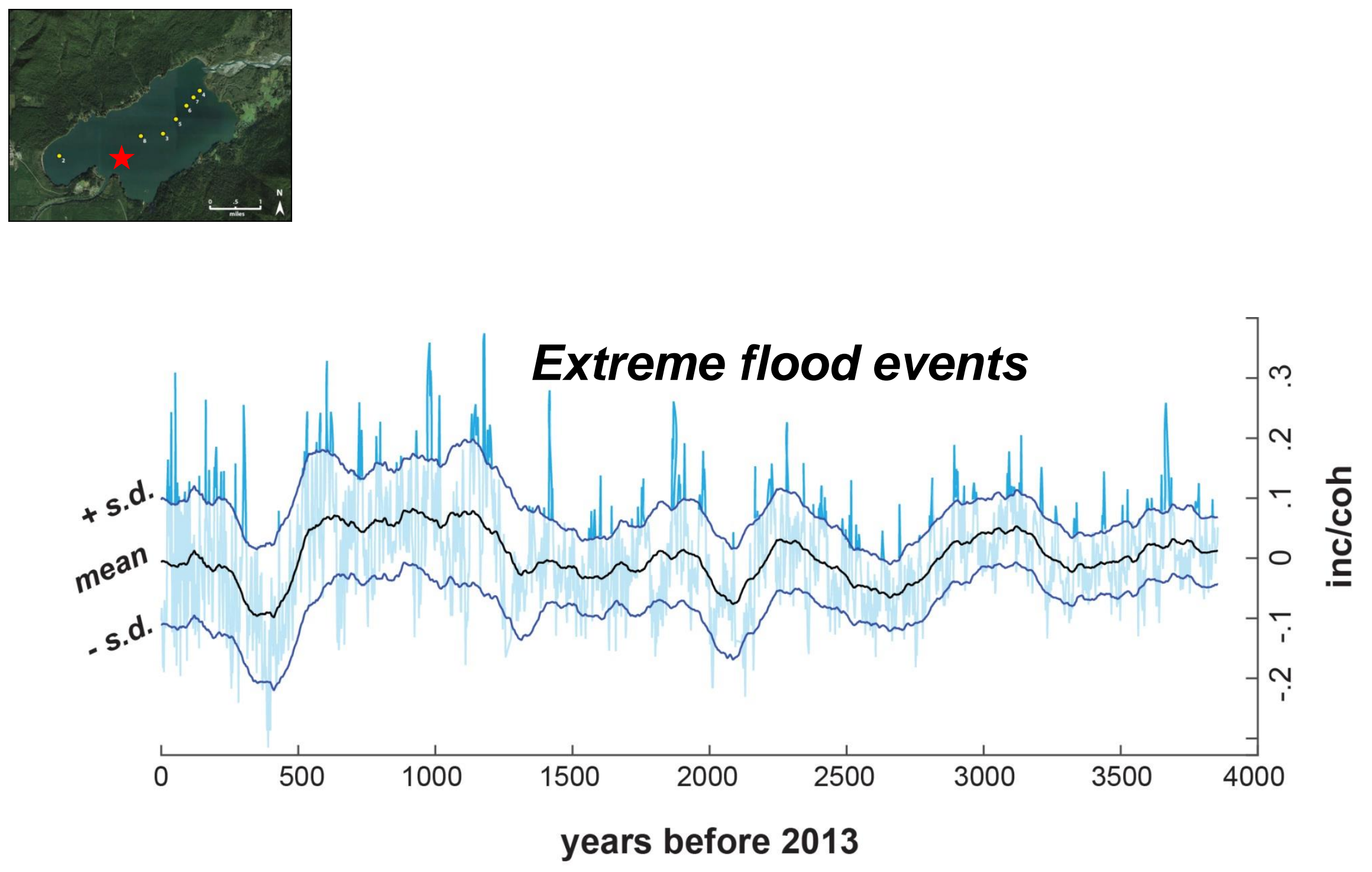


\section{Core 1}
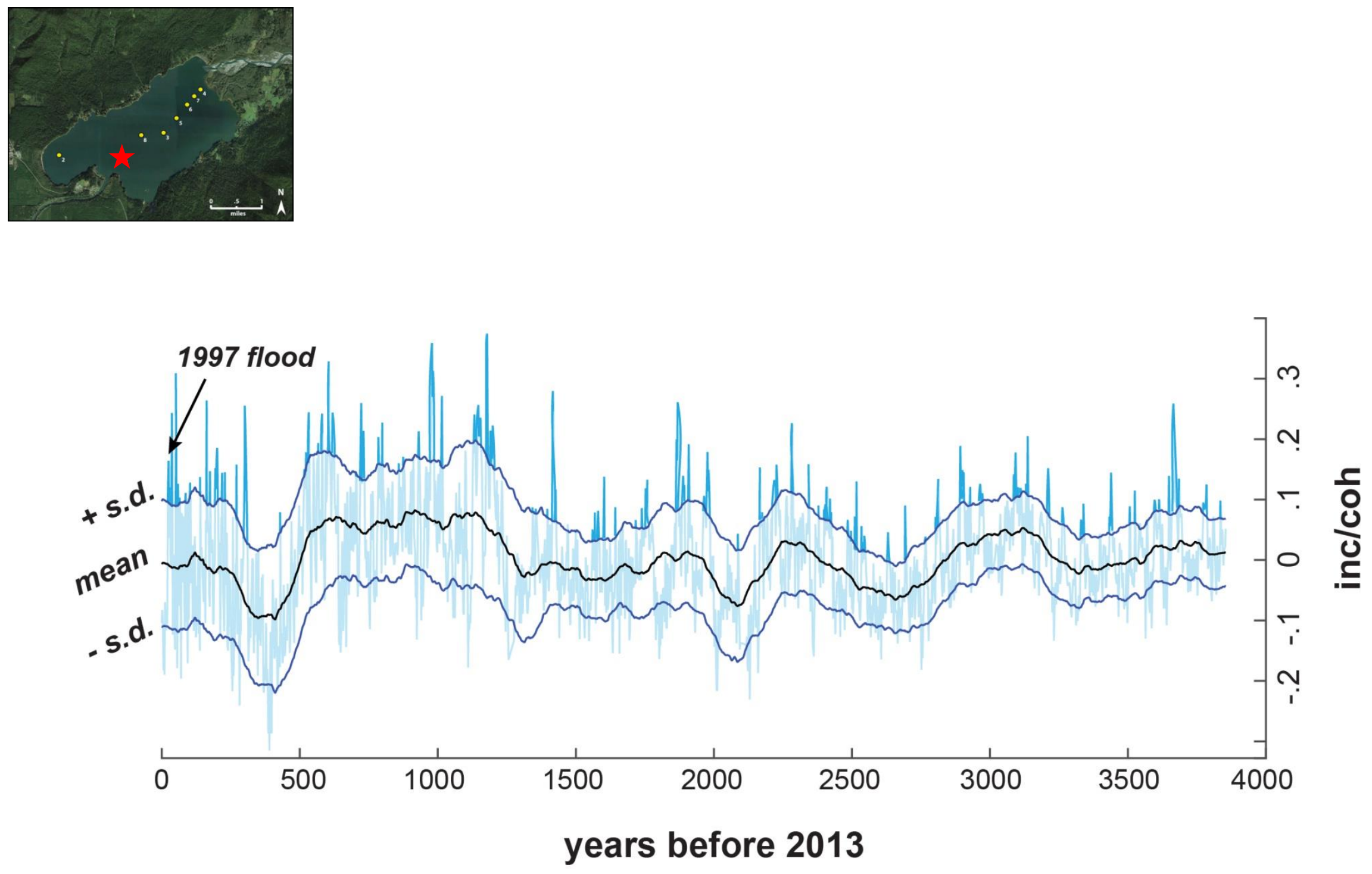


\section{Extreme floods through time}

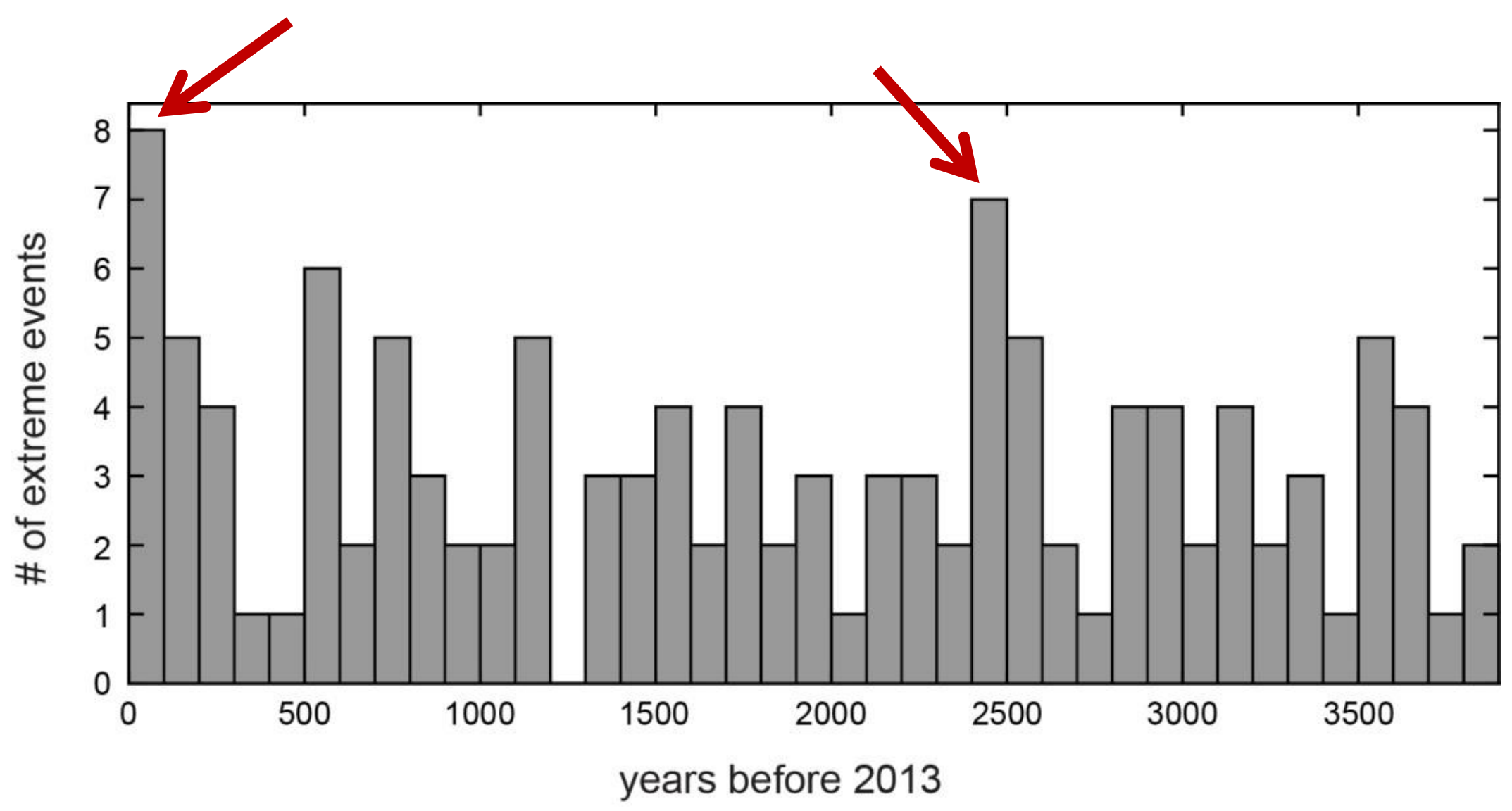




\section{Atmospheric rivers}

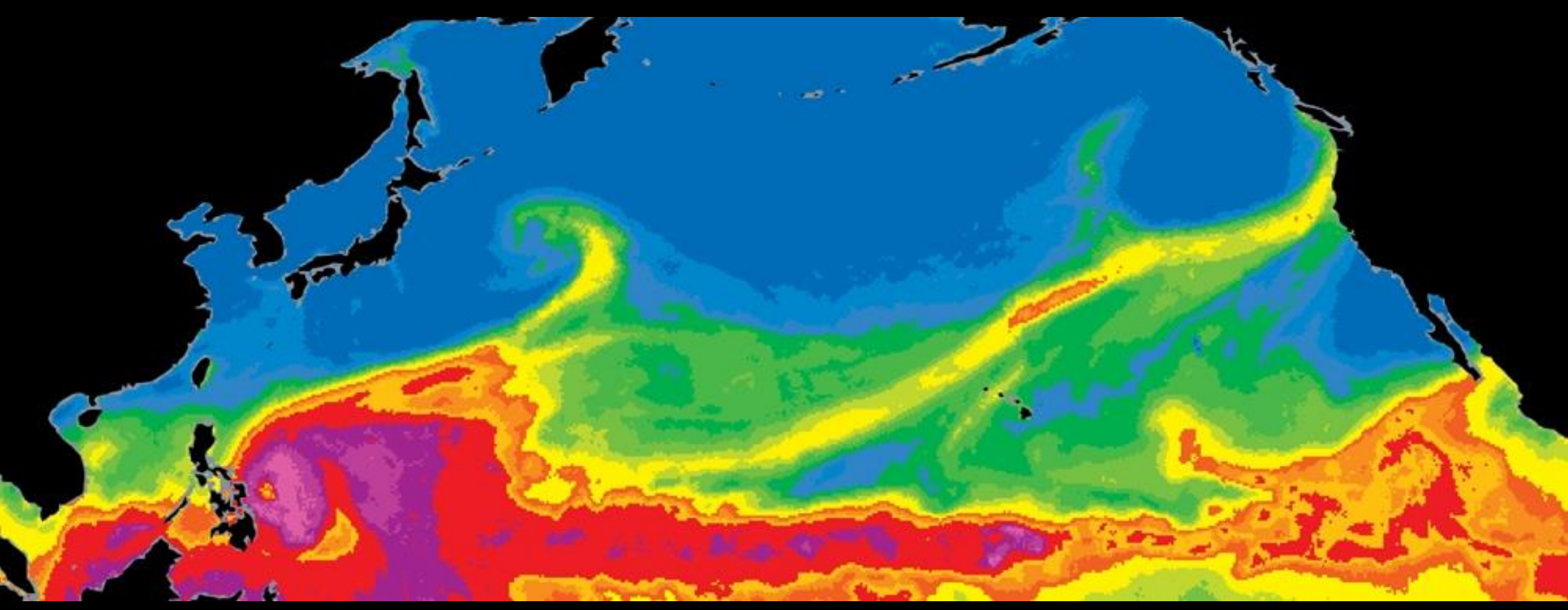


UW TWRF-GFS 36km Domain

Fest: $39 \mathrm{~h}$

Column-integrated water чаpor (mm)

$850 \mathrm{mb}$ Temperature (C)

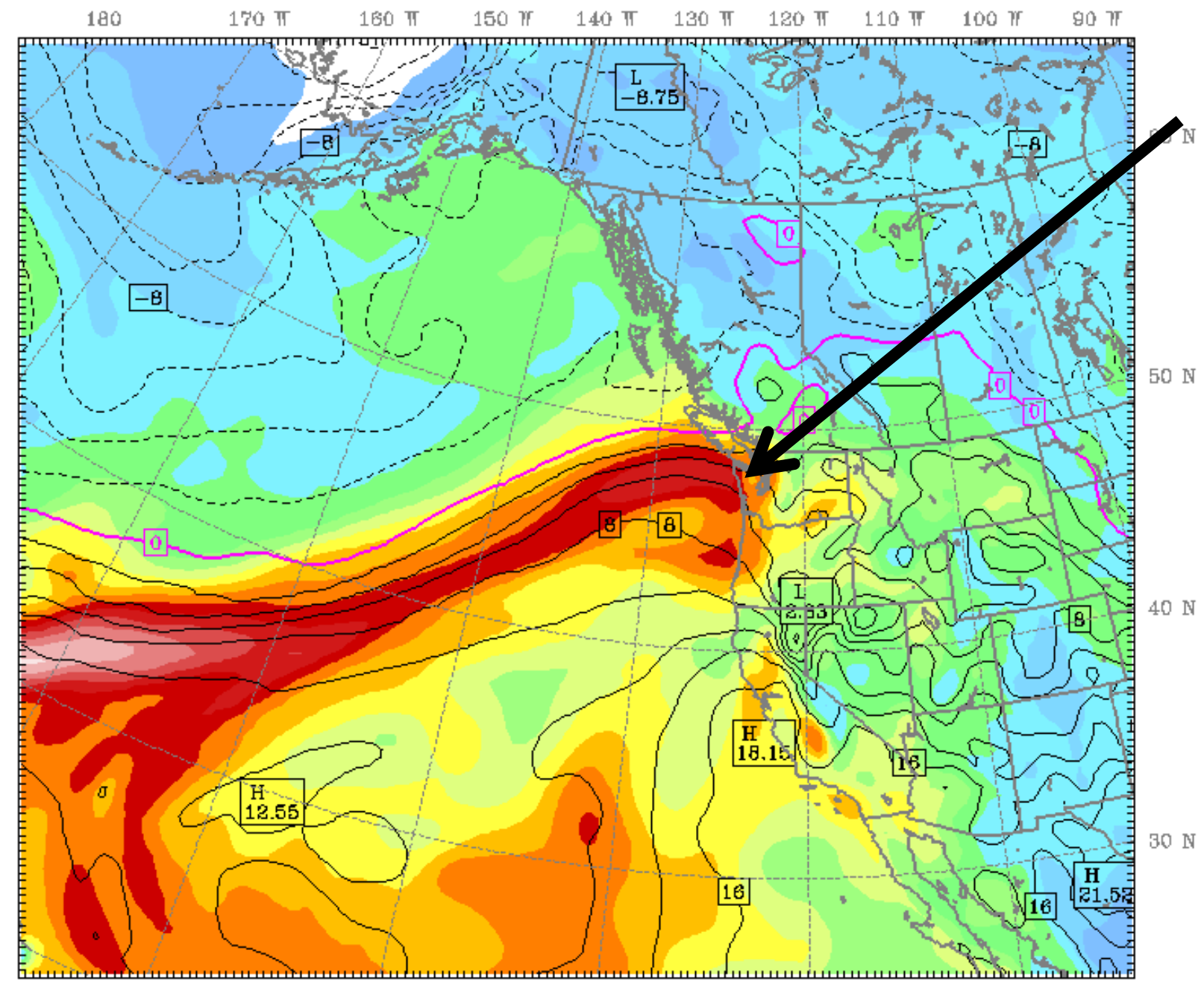

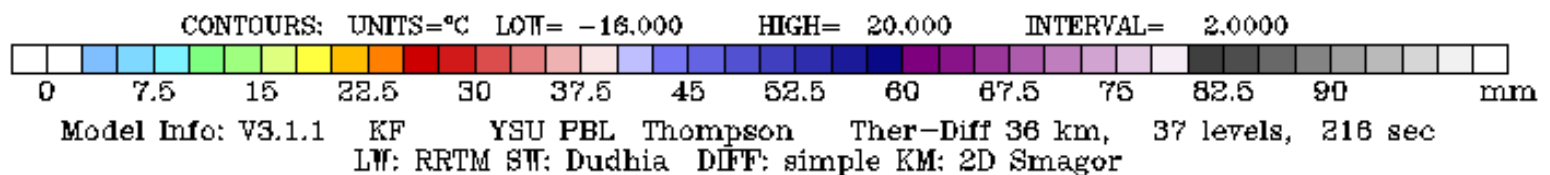




\section{Research Questions}

- Flood history from Lake Quinault...?

- $\mu X R F$ as a proxy...?

- Future of extreme events...? 


\section{Acknowledgements}

- Quinault Indian Nation, National Park Service, LacCore

- Karl Wegmann, Lonnie Leithold, Del Bohnenstiehl

- Bruce Riddell, Jubril Davies, Corey Moore, Deanna Metevier 